\title{
Coulisses
}

Revue de théâtre

19 | Hiver 1999

Varia

\section{Congrès mondial de l'AITU à Dakar}

Novembre 1999

\section{Robert Germay}

\section{(2) OpenEdition}

\section{Journals}

Édition électronique

URL : https://journals.openedition.org/coulisses/5648

DOI : $10.4000 /$ coulisses.5648

ISSN : 2546-9460

\section{Éditeur}

Presses universitaires de Franche-Comté

\section{Édition imprimée}

Date de publication : 1 janvier 1999

Pagination : 51

ISBN : 2-913322-09-3

ISSN : $1150-594 \mathrm{X}$

\section{Référence électronique}

Robert Germay, « Congrès mondial de l'AITU à Dakar », Coulisses [En ligne], 19 | Hiver 1999, mis en ligne le 18 octobre 2019, consulté le 09 janvier 2022. URL : http://journals.openedition.org/coulisses/ 5648 ; DOI : https://doi.org/10.4000/coulisses.5648

Ce document a été généré automatiquement le 9 janvier 2022.

Coulisses 


\section{Congrès mondial de l'AITU à Dakar}

Novembre 1999

Robert Germay

Le théâtre à l'université : jeu et enjeux ${ }^{1}$ 
1 Parce que sa nature est de parler de l'homme à l'homme, le théâtre n'est pas un jeu innocent: à travers l'histoire du théâtre, on aperçoit le reflet des changements de la société. Ceci s'applique parfaitement au théâtre à l'université! Son histoire (aussi longue que l'histoire de l'université elle-même) reflète les changements de société et, parallèlement, de l'université elle-même.

Théâtre de lettrés à ses origines, conforme alors à la tour d'ivoire universitaire, le théâtre étudiant $a$, depuis ces cinquante dernières années, percé des brèches en s'ouvrant de plus en plus vers le monde extérieur... comme l'université d'aujourd'hui. On peut même affirmer que le théâtre universitaire s'est forgé, depuis les années soixante, un label particulier dans le monde du théâtre tout court.
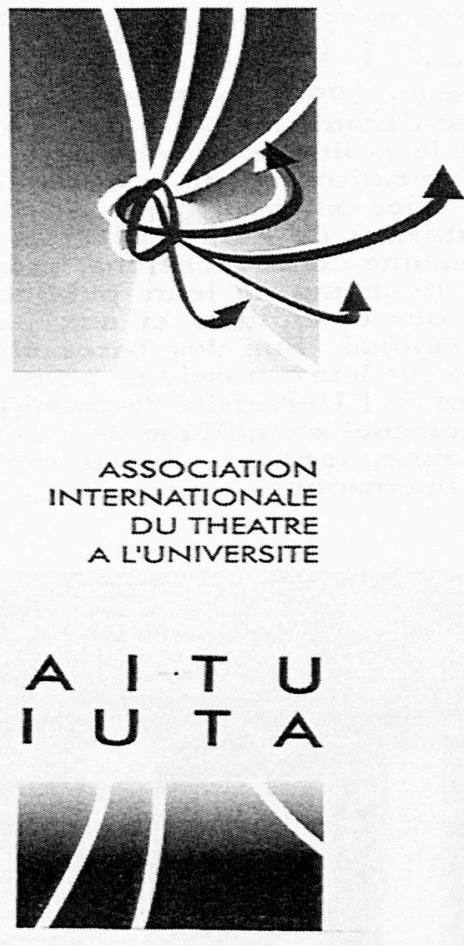

3 Il reste un jeu certes, car il doit continuer à procurer du plaisir, mais le théâtre universitaire représente aussi un enjeu important : pour celui qui le pratique; pour la recherche en théâtre à l'université ; pour la pratique théâtrale hors de l'université ; pour la formation professionnelle aux arts de la scène; pour les relations internationales et interculturelles, en particulier par la multiplication évidente de festivals internationaux et de coproductions transfrontalières.

4 La prise de conscience de ces enjeux et de leur importance comme outils de formation a conduit un nombre de plus en plus grand d'établissements d'enseignement supérieur dans le monde entier à accorder au théâtre, tant amateur pur que pré-professionnel, une place grandissante, allant jusqu'à l'inclure quelquefois dans les cursus de formation générale, même chez les scientifiques.

Cette prise de conscience a aussi généré l'Association internationale du théâtre à l'université, fondée à Liège en octobre $1994^{2}$, et qui tiendra son troisième Congrès mondial à Dakar en novembre 1999. En clôturant le Congrès fondateur de Liège, je disais : "En créant ici l'AITU, nous avons créé un carrefour. Il reste à y créer du mouvement... ». Si nous avons été plus nombreux encore à Valleyfield ${ }^{3}$ qu'à Liège, c'est qu'il y a eu du mouvement.

6 Il faut accélérer le mouvement, faire un plus grand pas encore en avant. Pour cela nous devons certainement, à l'intérieur de l'Exécutif, mieux définir les tâches respectives, ce qui permettrait de faire avancer - enfin - dans le concret, les différentes commissions (les moyens, l'information...) auxquelles nous avons rêvé. Lancer-enfin aussi-ce bulletin d'information périodique, dont voici le premier numéro, organe de liaison entre nous tous... et les autres. Nous sommes en bonne voie. Avançons. 


\section{NOTES}

1. Cet article reprend l'éditorial du premier numéro du Bulletin de liaison de l'AITU (Association internationale $\mathrm{du}$ théâtre à l'université) dont Robert Germay, responsable du Théâtre universitaire de Liège, est le président.

2. Voir Coulisses $n^{\circ} 14$, p. 64 , pour le compte rendu de ce premier Congrès. Sur l'AITU, voir aussi Coulisses $n^{\circ} 11$, p. 33, et Coulisses $n^{\circ} 18$, p. 70.

3. $\mathrm{II}^{\mathrm{e}}$ Congrès mondial, en juin 1997 . Voir son compte-rendu dans Coulisses $n^{\circ} 17, \mathrm{p} 63$.

\section{AUTEUR}

\section{ROBERT GERMAY}

Université de Liège 